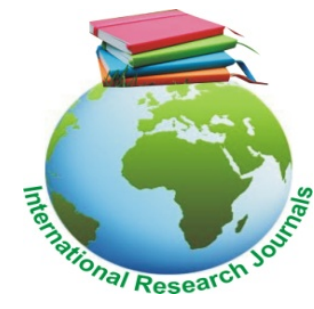

\title{
Seroprevalence and risk factors of toxoplasma gondii infection (toxoplasmosis) among hiv seropositive pregnant women in a tertiary healthcare centre, Kano, Northern Nigeria
}

\author{
Yusuf, A.M. ${ }^{1}$ Yahaya, S. $^{2}$ Azeez- Akande, $0 .^{1 *}$ \\ ${ }^{1}$ Department of medical microbiology and parasitology, college of health sciences, Bayero University, PMB 3011, Kano- \\ Nigeria \\ ${ }^{2}$ Department of microbiology, faculty of biological sciences, Bayero University, PMB 3011, Kano-Nigeria \\ Corresponding author's E-mail:aakande92@yahoo.com, Phone: +2348035893449
}

\begin{abstract}
Toxoplasmosis caused by an obligate intracellular Protozoan, Toxoplasma gondii has emerged as an important cause of opportunistic infection in HIVIAIDS resulting in severe morbidity and significant mortality. HIV infected pregnant women are prone to infection by $T$. gondii due to immune suppression and may lead to severe complications and congenital abnormalities. However, data on this subject matter are scarce in this environment. The study was aimed to determine the seroprevalence of $T$. gondii infection among HIV infected pregnant women and associated risk factors in Kano, northern Nigeria. A total of 273 HIV seropositive pregnant women attending Aminu Kano Teaching Hospital (AKTH), Kano were screened for $T$. gondii antibodies (IgG/lgM) by serology including determination of CD4 cell level in the patients by standard procedures. Socio-demographic information and risk factors variables of Toxoplasmosis including patient history were obtained via a questionnaire. Data were analyzed statistically. The overall (chronic and acute infections) seroprevalence of $T$. gondii infection in HIV pregnant women was $34.1 \%$; IgG, $30.8 \%$ versus IgM, $3.3 \%$. The age of patients ranged between $18-$ 39 years (mean age, $29.13 \pm 5.01)$. The highest seroprevalence $(39.8 \%$; IgG, $36.7 \%$ versus $\operatorname{lgM}, 3 \%)$ was found among the patients aged 31-40 years. Majority of the patients with chronic $T$. gondii infection (IgG, 72.4\%) and acute infection (IgM, 10.3\%) were found in those with CD4 cells count/ $\mu \mathrm{l}$ of $<200$, and 200-349 CD4 cell count/pl respectively. Data analysis showed that the subjects with regular contacts with cats and their litters including consumption of poorly prepared meat products were significantly associated with $T$. gondii infection $(P<0.05)$. The high $(34.1 \%)$ seroprevalence of $T$. gondii infection and chronicity (IgG, 30.8\%) in HIV infected pregnant women is concerning due to associated maternal and fetal complications. There is need for routine universal and antenatal screening for $T$. gondii in HIV seropositive pregnant women that will aid early detection and treatment to limit the spread of the disease and associated morbidity and mortality.
\end{abstract}

Keywords: Toxoplasmosis, seroprevalence, immunosuppression, pregnant women, morbidity, mortality.

\section{INTRODUCTION}

Toxoplasmosis caused by an obligate intracellular Protozoan, Toxoplasma gondii is an emerging infectious parasitic disease with increasing public health significance (Tenter et al.,2000; Caruthers, 2002). In the last two decades, $T$. gondii has evolved as an important cause of opportunistic infections in HIVIAIDS patients resulting in severe morbidity and significant mortality (Luft et al.,1992; James et al., 2009).

Macleod (1988) and Mims, et al (1998) reported that $T$. gondii has high potential to cause serious complications 
in HIV pregnant women, who are also predisposed to variety of other infections during gestational period due to immune suppression. Infection by $T$. gondii during pregnancy may lead to severe congenital abnormalities including premature delivery or still birth (Onadeko et al., 1996).

T. gondii infection is widespread among human population. Globally, the incidence of Toxoplasmosis varies among different population group (including HIV seropositive pregnant women) and ranges between 16$80 \%$ in different localities (Tenter et al., 2000). It accounts for $38 \%$ of opportunistic central nervous sytstem (CNS) infection, and $50-60 \%$ of intra-cerebral mass lesion in HIVIAIDS patients (Arora et al., 2009; Kistiah et al., 2011) In Nigeria, seroprevalence of Toxoplasmosis ranging from $16-30 \%$ have been reported among the general population (Mitchel et al., 1994; Onadeko et al.,1996). However, data on the burden of $T$. gondii infection among HIV infected pregnant women in this environment are scanty hence the need for the present study. The study was aimed to determine the seroprevalence of $T$. gondii and associated risk factors among HIV seropositive pregnant women in Kano, northern Nigeria. It is hoped that the outcome will further sensitize the populace on the need to adopt effective control measures that will checkmate the transmission of $T$. gondii infection among especially the HIV infected pregnant women to limit associated complications.

\section{MATERIALS AND METHODS}

\section{Study Area}

The study was carried out at Professor Sadiq Wali HIV treatment centre of Aminu Kano Teaching Hospital, Kano (AKTH). AKTH is a tertiary health care institution located in the large cosmopolitan city of Kano, northwest Nigeria. The hospital serves as a referral centre to the population of Kano state and neighboring states of Jigawa, Kastina, and parts of Kaduna.

Professor Wali centre is a large, well-equipped HIVIAIDS treatment clinic with over 18,000 registered patients and daily turn-over of 200 patients. It is supported by the Institute of Human Virology of Nigeria (IHVN); the President's Emergency Programme for AIDS Relief (PEPFAR, USA) project. The centre has both clinical and laboratory facilities for the screening/diagnosis and follow up of HIV infected patients. It also supports the prevention of mother to child transmission of HIVIAIDS programme (PMTCT).

\section{Study Design}

This was a cross sectional, prospective study involving 273 HIV seropositive pregnant women attending AKTH,
Kano, Nigeria between the month of January to December 2014, who gave consent for the study. The minimum sample size used in this study was obtained using the formula and procedure as described by Lwanga et al. (1991).

\section{Data Collection}

In each case, a questionnaire consisting of personal data and relevant risk factor variables of $T$. gondii infection was administered to record patient's socio-demographic information including name, age, occupation and educational qualifications, the kind of pets kept and methods of care; the type of food regularly prepared or procured and mode of preparation and consumption.

\section{Assays \\ HIV Serology}

The HIV status of the pregnant women was determined based on standard guidelines with DETERMINE HIV 112 (Abbott Comp. Ltd., Tokyo, Japan). All reactive samples were retested with STAT-PAK (Caldon Biotech, Inc., Carlsbad, CA, USA) for confirmation and reliability of results.

\section{CD4 Cell Count}

Ten millilitres (mls) of blood sample was collected from each patient by venipuncture and immediately emptied into a pre-labeled EDTA bottle. Three mls of the blood sample was withdrawn and immediately used for CD4 cell measurement by flow cytometry technique (Partec, flow, Germany). The manufacturer's instructions were followed methodically, and results were interpreted accordingly.

\section{Toxoplasma (T. gondii) Serology}

The remaining blood sample $(7 \mathrm{mls})$ was centrifuged at $3000 \mathrm{rpm}$ for 10 minutes and serum obtained. All sera collected were transferred into pre-labeled cryovials and stored at $-20{ }^{\circ} \mathrm{C}$ until analyzed. IgG and $\operatorname{lgM}$ were detected using the $\operatorname{lgG} / \mathrm{lgM}$ ELISA kit (Diagnostic automation Incorp. Carlsbad, CA, USA). Results were interpreted according to the manufacturer's instructions.

\section{Data Analysis}

Data were analyzed with Epi info (version 6.04, CDC, Atlanta, GA). The prevalence of $T$. gondii infection was expressed in simple proportion or percentages for the study group. Comparison of the group regarding the prevalence of infection, association between parasite 
Table 1: Seroprevalence (IgM and IgG) of Toxoplasma gondii among HIV infected pregnant women in Kano.

\begin{tabular}{lllll}
\hline $\begin{array}{llll}\text { Age range } \\
\text { (Yr.) }\end{array}$ & No examined & \multicolumn{2}{l}{ No (\%) positive for: } & Total no (\%) positive \\
\cline { 3 - 4 } & & & lgG & \\
\hline $11-20$ & 10 & $1(10)$ & $4(40)$ & $5(50)$ \\
$21-30$ & 165 & $5(3)$ & $44(26.7)$ & $49(29.6)$ \\
$31-40$ & 98 & $3(3)$ & $36(36.7)$ & $39(39.8)$ \\
Total & 273 & $9(3.3)$ & $84(30.8)$ & $93(34.1)$ \\
\hline
\end{tabular}

Table 2: Seroprevalence of $T$. gondii in relation to CD4 cell counts of the patients

\begin{tabular}{|c|c|c|c|c|}
\hline \multirow{3}{*}{ 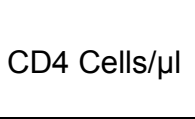 } & \multicolumn{2}{|c|}{$\lg G$} & \multicolumn{2}{|c|}{$\lg M$} \\
\hline & Positive & Negative & Positive & Negative \\
\hline & $\mathrm{n}(\%)$ & $\mathrm{n}(\%)$ & $\mathrm{n}(\%)$ & $\mathrm{n}(\%)$ \\
\hline$<200$ & $71(72.4)$ & $27(27.6)$ & $1(1.0)$ & $97(99.0)$ \\
\hline 200- 349 & $4(10.3)$ & $35(89.7)$ & $4(10.3)$ & $35(89.7)$ \\
\hline$\geq 350$ & $9(6.6)$ & $127(93.4)$ & $4(2.9)$ & 132(97.1) \\
\hline Total & $84(30.8)$ & 189(69.2) & $9(3.3)$ & 264(96.7) \\
\hline
\end{tabular}

infection and CD4 cell count and risk factors were analyzed using Chi- square test or two-tailed Fisher's exact tests for categorical variables and Student's t test for continuous variables.. A $p-$ value of $<0.05$ was considered statistically significant. The approval to conduct the study was sought and granted by the Ethical committee of the hospital (AKTH).

\section{RESULTS}

For this present study, a total of 273 HIV seropositive pregnant women aged 18-39years; mean age, 29.13 5.01 , were screened for $T$. gondii antibodies. The overall seroprevalence was $34.1 \%$ with $\lg$ G and $\lg M$ antibodies constituting $30.8 \%$ and $3.3 \%$ respectively (Table 1 ). The highest seroprevalence of $39.8 \%(\operatorname{lgG}, 36.7 \%$; $\operatorname{lgM}$, $3.1 \%$ ) was found among the patients aged $31-40$ years. Majority of the patients with chronic $T$. gondii infection (IgG, 72.4\%) and acute infection (IgM, 10.3\%) were found in those with CD4 cell count/ $\mu \mathrm{l}$ of $<200$, and

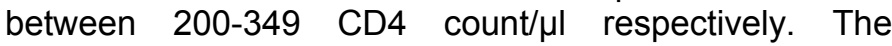
seroprevalence of Toxoplasma infection was significantly high $(72.4 \%)$ in those with CD4 cell/ $\mu$ l of $<200$ for IgG antibodies. Whereas in the analysis of IgM antibodies against $T$. gondii, the highest prevalence was found in patients whose CD4 cell count $/ \mu$ falls between 200 to less than 350. Significant association $(p<0.05)$ was found between $T$. gondii infection and CD4 cell counts for both IgG and IgM (Table 2).

Analysis of risk factors of Toxoplasmosis shows that HIV seropositive pregnant women with regular contact with cats were significantly associated $(p=0.002)$ with chronic $T$. gondii infection (IgG; $p=0.04$ ). However, on the basis of individual antibody seroprevalence, the highest prevalence of $\lg$ (40\%) and IgM (10\%) was detected among the patients in the age bracket 11-20 years (Table 1). Those who consistently handled cat litters were found to have significantly associated with chronic $T$. gondii infection (IgG; $p=0.02$ ).

\section{DISCUSSION}

Toxoplasma gondii is a coccidian Protozoan found worldwide (Arora et al., 2009). Infection with T. gondii (Toxoplasmosis) is believed to be widespread (incidence rate may be $\geq 80 \%$ in some localities) though with relative low mortality in immune-competent hosts (Bata et al., 2009). It is however, associated with severe morbidity, aggravated congenital defects in infected developing foetus, and increased mortality in immune compromised individuals such as HIVIAIDS (Luft et al., 1992; Onadeko et al., 1996). Emmanuel et al. (2011) reported that there are variations in the rate of occurrence of Toxoplasmosis in different localities and regions, and may be influenced by some risk factors.

In the present study, the overall seroprevalence (due to detection of $\lg$ and $\lg \mathrm{M}$ antibodies) of $T$. gondii among HIV seropositive pregnant women was 34.1 percent (Table 1).There was a preponderance (prevalence, $30.8 \%$ ) of chronic or latent form of Toxoplasmosis (due to presence of $\operatorname{lgG}$ antibodies) among infected pregnant women screening during the 
004 J. Med. Med. Sci.

Table 3: Seroprevalence of $T$. gondii in relation to the risk factors

\begin{tabular}{lcccc}
\hline Risk Factors & $\begin{array}{c}\text { Total No. of } \\
\text { Subjects }\end{array}$ & $\begin{array}{c}\text { Total No. Positive } \\
\text { (\%) }\end{array}$ & IgG(\%) & IgM(\%) \\
\hline Contact with cats & & & & \\
Yes & 103 & $66(64.1)$ & $62(60.2)$ & $4(3.9)$ \\
No & 170 & $27(15)$ & $22(12.1)$ & $5(2.9)$ \\
Total & 273 & $93(87.8)$ & $84(81.2)$ & $9(6.6)$ \\
Handling of Cat Litters & & $62(71.2)$ & $59(67.8)$ & $3(3.4)$ \\
Yes & 87 & $31(16.6)$ & $25(13.4)$ & $6(3.2)$ \\
No & 186 & $93(87.8)$ & $84(81.2)$ & $9(6.6)$ \\
Total & 273 & & & \\
Poorly cooked Meat & & $85(57.4)$ & $78(52.7)$ & $7(4.7)$ \\
Yes & 148 & $896.4)$ & $6(4.8)$ & $2(1.6)$ \\
No & 125 & $93(79.10$ & $84(72.3)$ & $9(5.3)$ \\
Total & 273 & & & \\
Source of Water & & $61(35.7)$ & $52930.4)$ & $9(5.3)$ \\
Pipe & 171 & $32(32.2)$ & $32(32.3)$ & $(0 .(0.0)$ \\
Well & 99 & $0(0.0)$ & $0(0.0)$ & $0(0 / 0)$ \\
Pond & 3 & $93(68)$ & $84(62.7)$ & $9(5.3)$ \\
Total & 273 & & & \\
\hline
\end{tabular}

Table 4: Seroprevalence of T. gondii according to socio-demographic characteristics of the HIV seropositive pregnant women

\begin{tabular}{lcccc}
\hline Characteristic & Total No. of Subjects & Total No. Positive (\%) & IgG(\%) & IgM(\%) \\
\hline Age (Yr.) & & & & \\
$11-20$ & 10 & $5(50.0)$ & $4940.0)$ & $1(10.0)$ \\
$21-30$ & 165 & $49(29.7)$ & $44(26.7)$ & $5(3.0)$ \\
$31-40$ & 98 & $39(39.8)$ & $36(36.7)$ & $3(3.1)$ \\
Total & 273 & $93(34.06)$ & $84(30.7)$ & $9(3.30$ \\
\hline
\end{tabular}

study (Table 1). This result is comparable with the prevalence of $29.1 \%$ and $31.5 \%$ previously reported by Bata and his colleagues (2009), and Emmanuel et al. (2011) respectively. However, it is lower than the figures ranging between $32.2 \%$ and $35.1 \%$ of IgG prevalence published elsewhere by various authors ( Zumla et al., 1991; Abu-Madi et al., 2010; Deji-Agboola et al., 2011). On the other hand, the seroprevalence of acute Toxoplasmosis (eliciting the presence of IgM antibodies) constitute 3.3 percent. This result falls within the range of 2.6-5.2\% reported by other investigators elsewhere outside Nigeria (Nijem, 2009; Abu-Madi et al., 2010; Cheesbrough, 2010).

The seemingly difference in the prevalence rates being reported by various researchers was probably due to the variation in the level of exposure to the risk factors of the disease by sampled population; their geographical location (as it relates to weather condition viz atmospheric temperature and humidity which affect the survival of $T$. gondii) (Kistiah et al., 2011), methodology (Pelloux et al., 1998) and sample size (Kistiah et al., 2011).

A significant association $(P<0.05)$ was observed between $T$. gondii infection and CD4 cell count in both chronic and acute cases (Table 2). The incidence of Toxoplasmosis was high in those patients with CD4 cell count of less than $200 \mathrm{cell} / \mu \mathrm{\mu}$. Similar observations had been reported elsewhere in Nigeria (Deji-Agboola, 2011) and outside the country (Koskiniemi et al 1989). This is not surprising as HIV infection is well known to contribute to the depletion of T-lymphocytes (CD4 cells) subpopulation and reduce immunity which predisposes the victims to various forms of opportunistic infections including T. gondii (Nijem, 2009).

Several studies (Tenter et al., 2000; Bata et al., 2009; Deji- Agboola et al., 2011) have shown human Toxoplasmosis to be dependent upon life style including keeping of pets and their management, sources of drinking water, nature and quality of animal products consumed and level of literacy among the populace. In previous reports (Nijem, 2009; Abu-Madi et al., 2010), regular contact with domestic animals such as cats and their litters were linked with $T$. gondi infection. We also observed similar scenario in the present study. For instance, majority of our subjects $(66,64.2 \%)$ had regular contact with domestic cats, while $60.2 \%$ (62 subjects) were regularly exposed to cat litters in their residents. Most positive cases for chronic or latent 
Toxoplasmosis were also recorded among these subjects (Table 3). Similarly acute cases of $T$. gondii infection were observed among exposed subjects but at reduced level of infection.

In the same manner, identical results were recorded among the patients who, at one time or another, consumed poorly prepared meats and/or having dug well as their main source of drinking water in their localities. The findings are in agreement with other reports where Toxoplasmosis has been associated with water borne transmission from especially well water contaminated with T. gondii (Bata et al., 2009; Sroka, 2010).

Transmission of $T$. gondii is believed to be predominantly common in rural areas and among those without any form of formal or western education as similarly observed in the present study (Table 4) (Koskiniemi et al., 1989).

The explanation of the previous authors was that, educated individuals were more enlightened and tend to observe greater personal and environmental hygiene than members of a community who never had any formal education and/or are consistently living in the rural areas where the parasite thrives. This may account for higher $T$. gondii infection in this group as was observed in the present study.

\section{CONCLUSION}

The high seroprevalence (34.1\%) of $T$. gondii infection among HIV infected pregnant women is concerning due to associated maternal and fetal complications including congenital defects. There is need for routine antenatal screening for $T$. gondii infection in HIV seropositive pregnant women for early detection and chemotherapy to limit associated morbidity and complications.

\section{ACKNOWLEDGEMENT}

We thank the Laboratory Scientists of Professor Wali Center at Aminu Kano Teaching Hospital for their technical support.

\section{REFERENCES}

Abu-Madi MA, Behnke JM, Prabhaker KS, Al- Ibrahim R, Lewis JW (2010). Intestinal Helminthes of Feral Cat Populations from Urban and Suburban District of Qatar. Vet. Para. 168: 284-292.

Alvarado-Esquivel C, Estrada-Martínez S, Liesenfeld O (2011). Toxoplasma gondii Infection in Workers Occupationally Exposed to Unwashed Raw Fruits and Vegetables: A Case Control Seroprevalence Study. Parasite Vect. 16:224-235.

Arora DR, Arora B (2009). Toxoplasma gondii In: Medical Parasitology $2^{\text {nd }}$ edition, CBS Publishers, New Delhi, p. 83-88.

Bata SI, Ikwe A, Jalatau UU, Idris L, Randawa AJ (2009). Seroprevalence and Risk Factors for Toxoplasma gondii Infection Among Antenatal Women in Zaria, Nigeria. Res. J. Med. Medic. Sc. 4(2): 483-488.
Caruthers VB (2002). Host Cell Invasion by the Opportunistic Pathogen, Toxoplasma gondii. Acta. Trop. J. 81: 111-122.

Cheesbrough M (2010). Diagnosis of Toxoplasmosis. District Laboratory Practice in Tropical Countries, Part 1. Second Edition Update. Cambridge University Press. Cambridge P. 300-309.

Deji-Agboola AM, Busari OS, Osinupebi OA, Amoo OJ (2011). Seroprevalence of Toxoplasma gondii Antibodies Among Pregnant Women Attending Antenatal Clinic of Federal Medical Center, Lagos, Nigeria. Intern. J. Biol. Med. Res. 2(4): 1135 - 1139.

Emmanuel CU, Raymond A, Jude O, Hannah E, Lawrence E (2011). Comparative Seroprevalence and Risk Factors of Toxoplasmosis Among Three Subgroups in Nigeria. J. Natur. Sc. Res. 3: 8-10.

James DC, Gail JH, Sheldon LK, William JS, Peter JH (2009). Toxoplasmosis Causes, Diagnosis and Treatment, 5th Edition, Elsevier Publisher, Amsterdam. p. 2986-3005.

Kistiah KBA, Winiecka-Krusnell J, Karstaedt A, Frean J (2011). Seroprevalence of Toxoplasma gondiiinfection in HIV positive and HIV Negative Subjects in Gauteng, South Africa. South Afri. J. Epidemiol. Infect. 26 (4): 225-228.

Koskiniemi M, Lappalainen M, Hedman K (1989). Toxoplasmosis Needs Evaluation, An Overview and Proposals. Am. J. Dis. Child. 143:724728.

Luft BJ, Remington JS (1992). Toxoplasmic Encephalitis in AIDS Patients. Clin. Infect. Dis. 15: 211-222.

Lwanga S, Lemeshow S (1991). Sample Size Determination in Health Studies: A Practical Manual. World Health Organization, Geneva

Macleod CL (1988). Parasitic Infections in Pregnancy. C.L. Macleod (Editor), Oxford University Press, Oxford.

Mims C, Playfair J, Roitt I, Wakelin D, William R (1998). Obstetric and Perinatal Infection In: Medical Microbiology, $2^{\text {nd }}$ edition, Mosby International Ltd. London, p. 287-312.

Mitchell CD, Pizzo PA, Wilfert CM (1994). Toxoplasmosis In: Paediatric AIDS; the Challenge of HIV Infection in Infants, Children and Adolescents. $2^{\text {nd }}$ edition. Williams and Wilkins Publishers, Baltimore. p 419-431.

Nijem K (2009). Seroprevalence and Associated Risk Factors of Toxoplasmosis in Pregnant Women in Hebron District, Palestine. East.Mediterr Health J. 15:1279-1284.

Onadeko MO, Johnson DH, Payne RA, Francis J (1996). The Prevalence of Toxoplasma Antibodies in Pregnant Women and the Occurrence of Stillbirth and Congenital Malformations. Afr. J. Med. Medic Sc. 25:331-334.

Pelloux H, Burn E, Vernet G, Marcilat S, Jolivet M (1998). Determination of Anti-Toxoplasma gondii Immunoglobulin G Avidity: Adaptation to the VidasSystem. Diagn. Microbiol. Infect. Dis. 32: 69-73.

Sroka JW, Szymanska J, Dutkiewicz J, Zajac V, Zwolinski J (2010). The Occurrence of Toxoplasma gondii Infection in People and Animals from Rural Environment of Lublin Region - Estimate of Potential Role of Water as a Source of Infection. Ann. Agric. Environ. Med. 17(1):125-132.

Tenter AM, Heckeroth AR, Weiss LM (2000). Toxoplasma gondii: from Animals to Humans. Intern J. Parasitol. 30: 1217-1258.

Zumla, A., Savva D, Wheeler RB (1991). Toxoplasma serology in Zambian and Ugandan Patients Infected with the Human Immunodeficiency Virus. Transact. Roy. Soc. Trop. Med. Hyg. 85: 227-9. 